\title{
Adsorption of Silicate Anions from Geothermal Brine Using Chitosan-Polyethylene Glycol Composite to Prevent Silica Scaling on the Dieng Geo Dipa Geothermal Energy System
}

\author{
Nur Hayati ${ }^{1}$, Hanik Humaida ${ }^{2}$, and Dwi Siswanta ${ }^{{ }^{*}}$ \\ ${ }^{1}$ Department of Chemistry, Faculty of Mathematics and Natural Sciences, Universitas Gadjah Mada, \\ Sekip Utara, Yogyakarta 55281, Indonesia \\ ${ }^{2}$ Institute for Investigation and Development of Geological Disaster Technology, Jl. Cendana no. 15, Yogyakarta 55166, Indonesia
}

\section{*Corresponding author:}

email:dsiswanta@ugm.ac.id

Received: September 2, 2019

Accepted: November 1, 2019

DOI: $10.22146 /$ ijc. 49248

\begin{abstract}
Silica scaling is a common problem in geothermal power generation facilities which inhibits electricity generation. In order to provide a solution to this problem, the removal of silicate ions using CPEG-TOMAC (Chitosan-polyethylene glycol-trioctyl methyl ammonium chloride) membrane adsorbent was investigated for geothermal brine from Geo Dipa Energy, Dieng. The process is dependent on contact time, $p H$, and the concentration of silicate. An adsorption batch study that used adsorbents for the geothermal brine of the Dieng Geo Dipa reactor 28A showed that CPEG TOMAC at pH 6 resulted in an adsorption capacity of $72.6 \mathrm{mg} \mathrm{g}^{-1}$. Furthermore, the adsorption of silicate ions onto the membrane followed pseudo-second-order kinetics and the Freundlich isotherm model.
\end{abstract}

Keywords: silica scaling; geothermal brine; chitosan; adsorption; silicate ion

\section{- INTRODUCTION}

The geothermal potential in Indonesia is relatively high, which is indicated by the 117 active volcanoes that spread across the country [1]. Furthermore, it is estimated that Indonesia owns $40 \%$ of the world's geothermal energy potential or about 28.617 MW. However, only about $4.5 \%$ is being utilized as electrical energy [2-3]. The Dieng plant is one of the geothermal power plants in Indonesia with an installed capacity of $60 \mathrm{MW}$ supplied by steam from eight production wells at four locations [4]. Silica scaling inhibits electricity generation and is also a common problem in geothermal power plants [5,7] because scaling decreases the flow capacity of geothermal fluid in the pipeline network. Chemical analysis of the Dieng brine indicated high silica and salt concentration.

Silica solubility depends on many factors such as $\mathrm{pH}$, temperature, and the presence of organic and inorganic matter [6]. The polymorphs of this compound, both crystalline and amorphous, have essentially constant solubility between $\mathrm{pH} 2$ and 8.5 but increases rapidly from 9 onwards [7]. However, the solubility is highly affected by temperature, i.e., $\quad 100-140 \mathrm{ppm}$ at ambient temperature and $300 \mathrm{ppm}$ at $70{ }^{\circ} \mathrm{C}[3,8]$.

There are numerous silica removal techniques, including chemical dosing of lime, aluminum, or iron salts, antiscalant [9-10], electrocoagulation [11-12], adsorption [13-14], ion exchange [15-16], and seeded precipitation [5]. Adsorption is a good solution for silica scale, which has a high capacity and is used for a specific $\mathrm{pH}$ level [17-18]. The mechanism employed in this process involved the removal of silica in ionic form from the solution by adsorption onto active sites on the surface of the adsorbent material. Aluminum-based adsorbents appear to give the best result $[11,19]$. Generally, metal based adsorbents harm the environment because of their toxic nature towards organisms, but the adsorbents based on organic compounds are environmentally friendly [18-21].

Rajeswari (2015) has successfully synthesized PEG/chitosan (CPEG) composite material, and it was used to remove phosphate from a water system [22]. The material can adsorb this ion because phosphate $\left(\mathrm{HPO}_{4}{ }^{2-}\right)$ 
is an anion that is attracted to the $\mathrm{NH}_{4}{ }^{+}$sites of the CPEG [22]. Silica dissolves in water as $\mathrm{H}_{2} \mathrm{SiO}_{4}^{-}$, and the composite material was discovered to be effective for removing $\mathrm{H}_{2} \mathrm{SiO}_{4}{ }^{-}$in geothermal fluid from the Dieng Geo Dipa Power Plant.

Trioctyl methyl ammonium chloride (TOMAC) is an emulsifier that increases the solubility of curcumin in chitosan-pectin material [23], and the molecules have hydrophilic and hydrophobic groups [24]. As a surfactant added in the CPEG, TOMAC does not form chemical bonding in the composite but forms micelles between the material components. In addition, it is estimated to increase the adsorption capacity of CPEG which is optimizable with TOMAC at certain concentrations and $\mathrm{pH}$ levels.

\section{- EXPERIMENTAL SECTION}

\section{Materials}

All chemicals were obtained from Sigma Aldrich, which includes chitosan with a $90 \%$ degree of deacetylation (80 mesh), polyethylene glycol, stock solution of silicate, nitric acid $\left(\mathrm{HNO}_{3} 1 \mathrm{~N}\right)$, acetic acid (2\%), and trioctyl methyl ammonium chloride (TOMAC).

\section{Instrumentation}

The FTIR spectra were recorded on Shimadzu Prestige-21 FTIR spectrophotometer with the $\mathrm{KBr}$ pellet method. The other instruments used were AAS Perkin Elmer 400 and SEM-EDS FEI FEG Quanta 650.

\section{Procedure}

\section{Preparation of CPEG composites}

Chitosan was dissolved in $2 \%$ acetic acid using a mechanical stirrer, while PEG was dissolved in distilled water in another beaker. Then, PEG was added to the chitosan solution and blended by the stirrer in a boiling water bath for $2 \mathrm{~h}$. Afterward, extra chitosan was then put into the solution, shaken at $80{ }^{\circ} \mathrm{C}$ for $6 \mathrm{~h}$. Finally, this solution was poured and cooled on a Petri dish for 3 days until the material was dried and then used as an adsorbent. Furthermore, the TOMAC added to the membrane mixture was varied as $0,1,3$, and $5 \%$ by weight of the membrane.

\section{Adsorbent characterization}

The IR spectra of the membranes were recorded by Fourier Transform Infrared Spectrometer (FTIR), while the surface morphology and elemental composition of the adsorbent before and after the adsorption process were analyzed by using a Scanning Electron Microscopy (SEM).

\section{Adsorption experiments}

Batch adsorption experiments were carried out, where about $0.1 \mathrm{~g}$ of the membrane was immersed into $50 \mathrm{~mL}$ of $20 \mathrm{mg} \mathrm{L}^{-1}$ adsorbate solution at the temperature of $90^{\circ} \mathrm{C}$. At first, the silicate adsorption efficiency of the membrane was studied with varying parameters of $\mathrm{pH}$ (3-9) and contact time (10-60 min). Then, the sample from PLTP Geo Dipa Dieng was interacted with the adsorbent in the same condition.

\section{Sampling method}

The sample was obtained from PLTP Geo Dipa Dieng, in which the temperature, pressure, and $\mathrm{pH}$ features of the location were measured before sampling. The water baler or dipper was rinsed twice, while the sample was stored in bottles and acidified to $\mathrm{pH}<3$ by $\mathrm{HNO}_{3}$ solution.

\section{- RESULTS AND DISCUSSION}

\section{Preparation and Characterization of CPEG Composites}

CPEG composite was prepared by using the same method as reported previously [22]. Fig. 1 shows the FTIR spectra of CPEG and CPEG-TOMA alongside PEG and chitosan.

Fig. 1(a) shows the vibration peak of PEG, a polymer that shows a bending vibration of $\mathrm{C}-\mathrm{H}$ at $1456 \mathrm{~cm}^{-1}$ and $-\mathrm{C}-\mathrm{H}$ stretching at $2869 \mathrm{~cm}^{-1}$. The vibrations peak of -OH PEG appears at $3500 \mathrm{~cm}^{-1}$. The vibrations of the functional group of chitosan in Fig. 1(b) show a characteristic peak at $1571 \mathrm{~cm}^{-1}$, stretching of $\mathrm{C}=\mathrm{O}$ at $1656 \mathrm{~cm}^{-1}$, and hydroxyl vibration at $3478 \mathrm{~cm}^{-1}$. CPEG membrane shows that a characteristic peak at $3424 \mathrm{~cm}^{-1}$ is attributed to stretching the vibration of $-\mathrm{NH}$ and $-\mathrm{OH}$ groups of the chitosan matrix, while the amide peaks of this polysaccharide are slightly shifted to 1632 and $1525 \mathrm{~cm}^{-1}$. The shifts were possibly due to the 


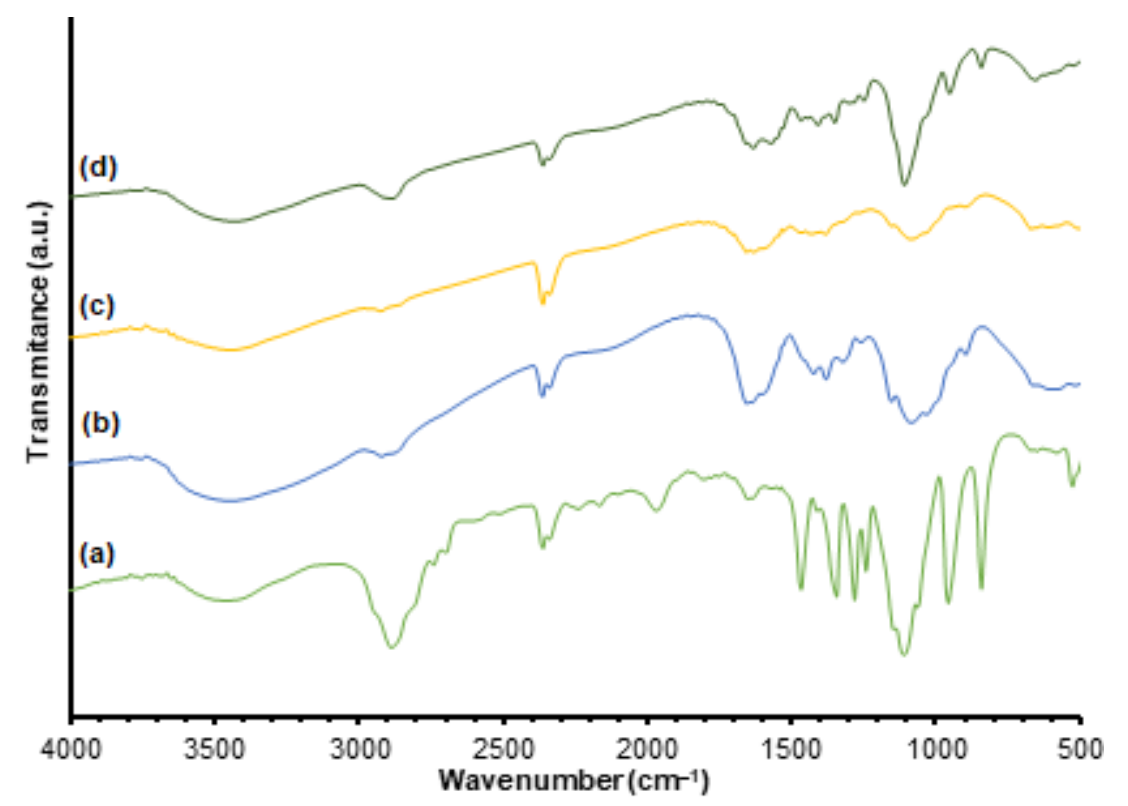

Fig 1. FTIR spectra of (a) PEG, (b) chitosan, (c) CPEG, and (d) CPEG-TOMA

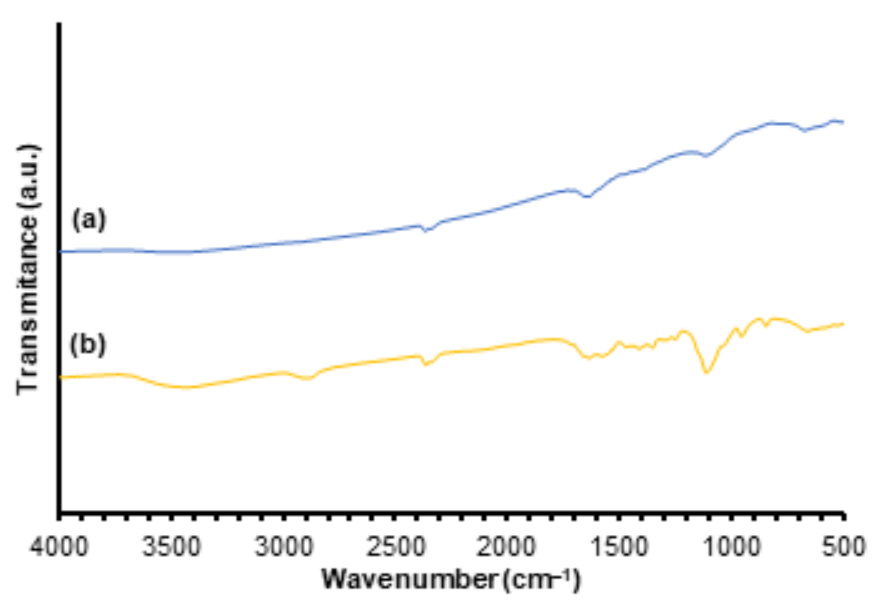

Fig 2. FTIR Spectra of CPEG (a) before and (b) after adsorption of silicate

presence of hydrogen bonding between the amide carbonyl and the PEG hydroxyl. The absorption band at $1382 \mathrm{~cm}^{-1}$ indicated the bending vibrations of $\mathrm{C}-\mathrm{H}$. Furthermore, the increased intensity of the peaks at around 2884 and $1100 \mathrm{~cm}^{-1}$ indicated the stretching vibration of the $\mathrm{CH}$ groups and the $\mathrm{C}-\mathrm{O}-\mathrm{C}$ of $\mathrm{PEG}$. The disappearance of peaks at 953 and $839 \mathrm{~cm}^{-1}$ is attributed to the formation of CPEG as a composite material.

IR spectra of the CPEG-TOMA membrane before and after adsorbing silicates are shown in Fig. 2. A peak at $3472 \mathrm{~cm}^{-1}$ is attributed to $-\mathrm{OH}$ groups stretching vibration in the CPEG-TOMA matrix, while the one at
$1636 \mathrm{~cm}^{-1}$ indicated $-\mathrm{NH}$ vibration. Furthermore, the peak at $1119 \mathrm{~cm}^{-1}$ indicated the stretching vibration of the $\mathrm{C}-\mathrm{H}$ groups and the $\mathrm{C}-\mathrm{O}-\mathrm{C}$ of CPEG-TOMA. Therefore, the three peaks have low intensity because $-\mathrm{NH}$ groups have interacted with the silicate anions. The active site of chitosan $\left(-\mathrm{NH}_{3}{ }^{+}\right)$interacted with $\mathrm{H}_{3} \mathrm{SiO}_{4}{ }^{-}$ by electrostatic force, which affected the intensity and peak position of the $-\mathrm{NH}_{2}$ group.

The existence of silicate on the CPEG membrane before and after adsorption was confirmed using SEMEDS, as shown in Fig. 3. The EDS spectra confirmed the adsorbent composition after the adsorption process. However, the elements such as $\mathrm{C}, \mathrm{O}, \mathrm{N}$, and $\mathrm{Cl}$ still appear because they are the main constituent of the raw material. After the process, silica $(\mathrm{Si})$ present as the dissolved form in the geothermal fluid was absorbed onto the CPEG with $1 \%$ TOMAC. In addition, the membrane also had a high-intensity chlorine peak as the Geo Dipa Dieng plant has a chlorine type reservoir with relatively high chloride ion concentrations.

\section{Effect of TOMA Addition}

Fig. 4 shows the SEM images of the synthesized samples with the variation of the TOMA concentration. The TOMAC addition to the CPEG resulted in the change in the porosity of the material, but no significant 


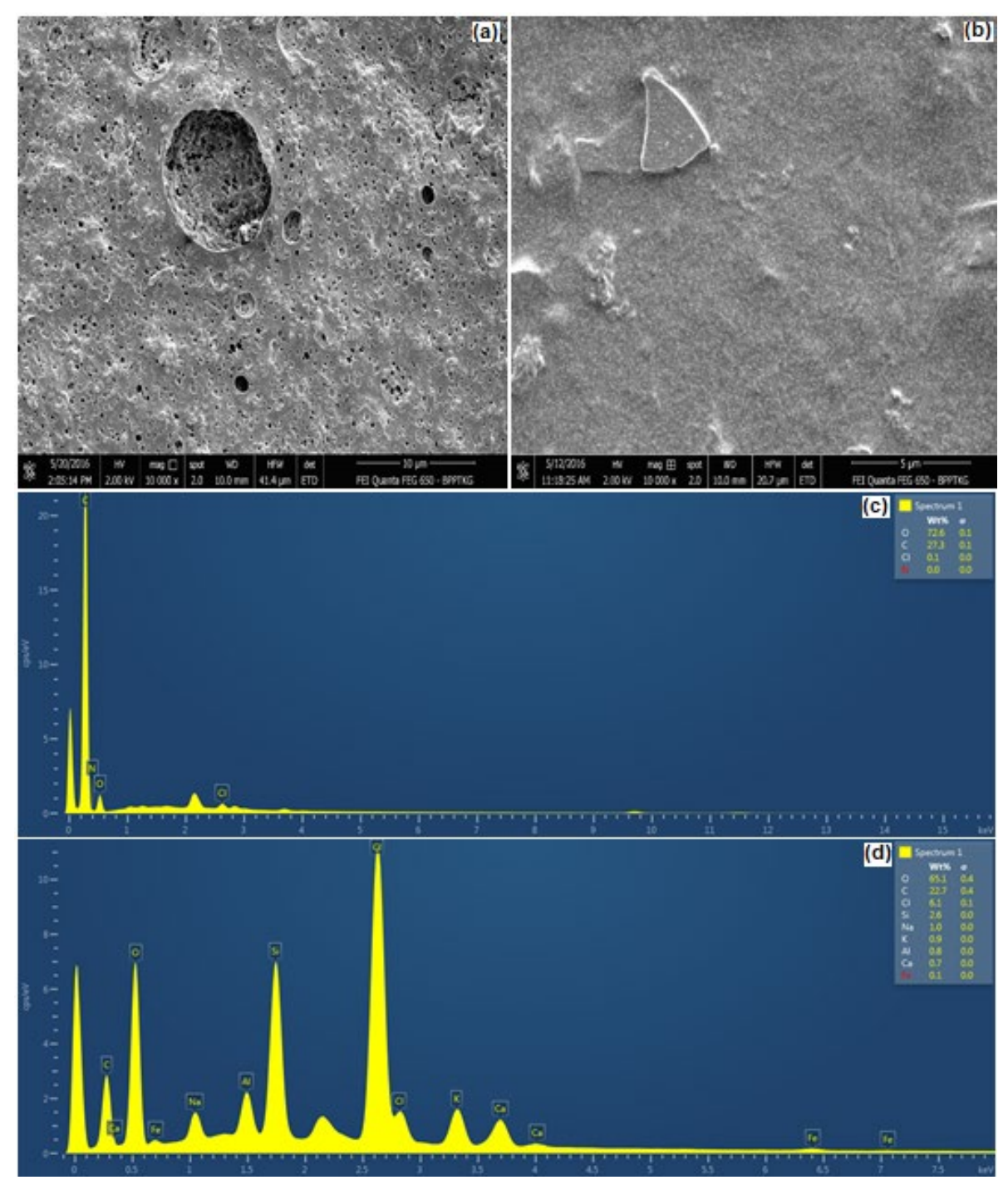

Fig 3. SEM image of (a) CPEG-1\% TOMA, (b) adsorbed silicate on CPEG 1\% TOMA, and EDS spectra of CPEG 1\% TOMA (c) before adsorption, (d) after adsorption of silicate

change in regards to that effect was shown upon increasing the concentrations of the surfactant from 1 until $5 \%$.

\section{Effect of $\mathrm{pH}$}

The effect of $\mathrm{pH}$ was determined at three different levels namely $\mathrm{pH} 3,6$, and 9 . The variation was conditioned based on the geothermal reservoir condition, i.e., acidic condition at $\mathrm{pH} 3$, neutral condition at $\mathrm{pH} 6$, and basic condition at $\mathrm{pH} 9$. The adsorption of silicate by the CPEG composite membrane at various $\mathrm{pH}$ levels is shown in Fig. 5.

The results indicated that the $\mathrm{pH}$ of solutions had an influence on the adsorption of silicate onto CPEG. The highest adsorption capacity obtained at $\mathrm{pH} 6$ was mainly due to strong electrostatic interaction between the positively charged sites of the adsorbent. In this case, the adsorbent is suitable to remove the silicate anions of the Dieng Geo Dipa brine.

\section{Effect of Silicate Concentration}

The effect of the initial concentration of silicate on the adsorption capacity of the adsorbent is shown in Fig. 6 , and these data were used to determine the adsorption isotherm model. Increasing silica concentration reduces the percentage of adsorption, but the membrane's capacity elevates by increasing the initial concentration. 

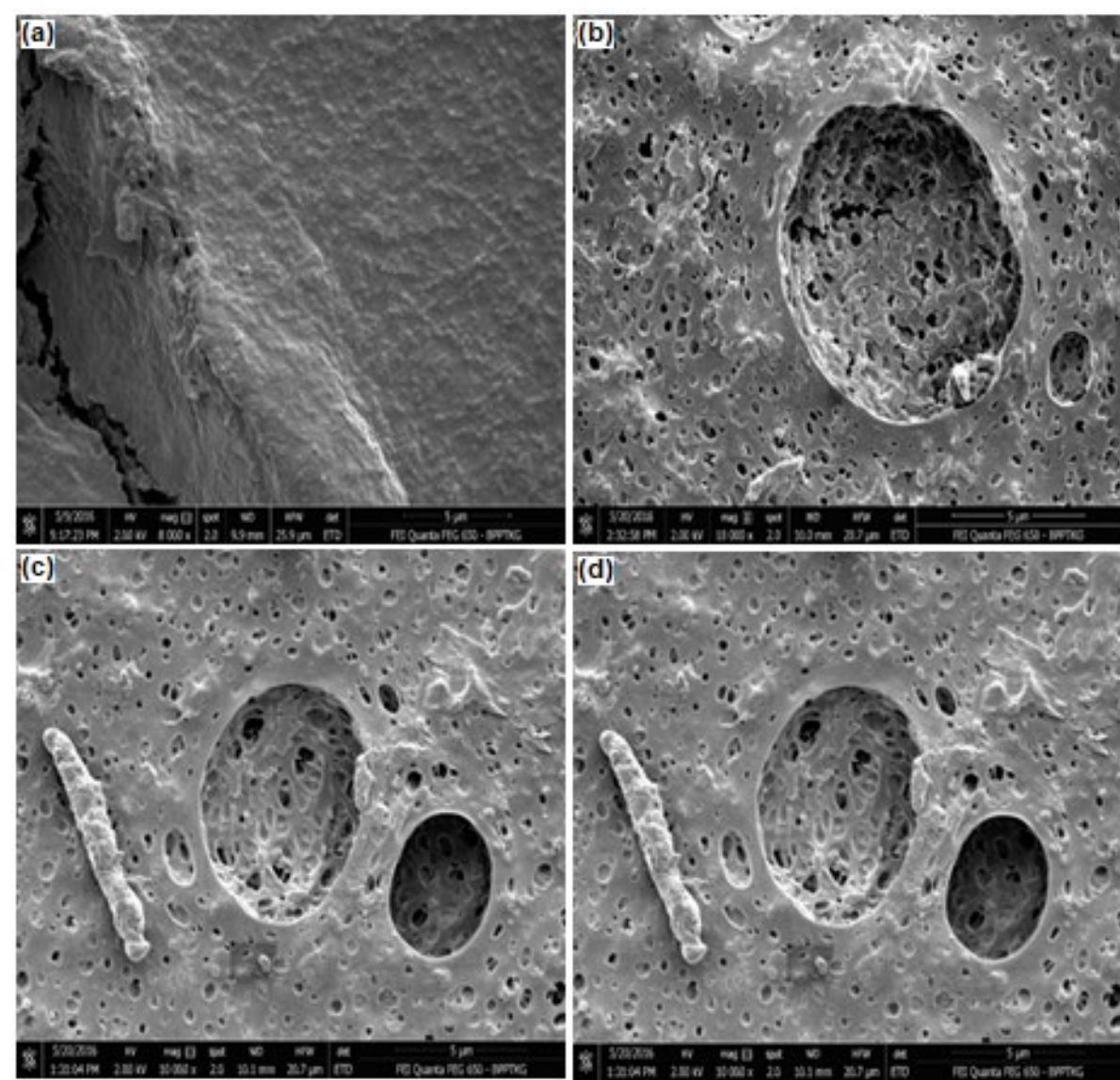

Fig 4. SEM image of CPEG membrane (a) 0\% TOMAC, (b) 1\% TOMAC, (c) 3\% TOMAC, (d) 5\% TOMAC

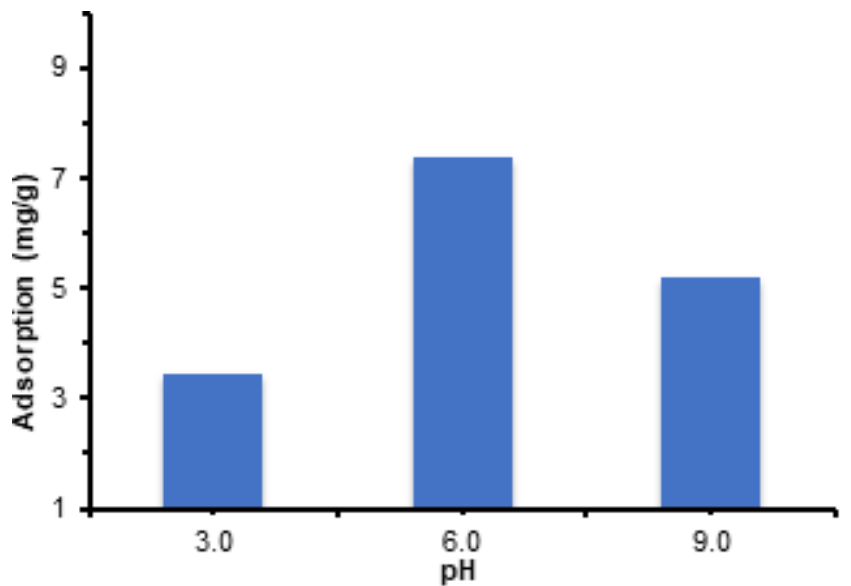

Fig 5. Effect of $\mathrm{pH}$ on the adsorption capacity of the CPEG composite material

At a low amount of the compound, the membrane still has abundant active groups to ensure that almost all anions are attached to it subsequently. The increase in concentration caused the number of active groups filled with silicate anions to elevate reaching the maximum

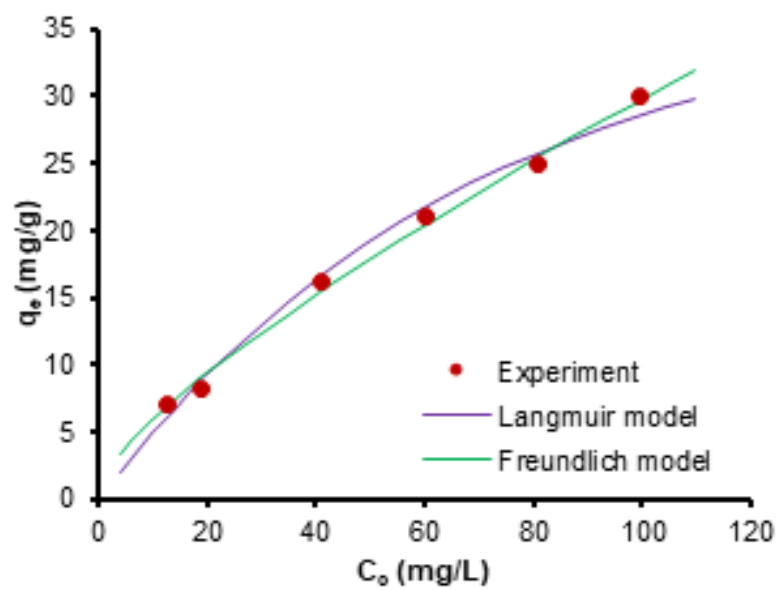

Fig 6. Effect of silica concentration on the adsorption capacity of the material

level, which results in the inability to bind more adsorbate. The continuous increase in the attached silicate anions caused a rise in the interaction with the available active sites. The increase in the interaction continues until the surface of the adsorbent is saturated, 
or when the active site is no longer available. Based on these data, an adsorption isotherm model was determined. The adsorption isotherm helps describe the interaction between the adsorbent (CPEG composite membrane) and the adsorbate (dissolved silica), the surface properties of the adsorbent, and its capacity. The isotherm models used in this study are the Langmuir and the Freundlich models.

The silicate adsorption capacity of the CPEG composites was been evaluated using the Langmuir isotherm model as given in Eq. (1):

$\frac{\mathrm{C}_{\mathrm{e}}}{\mathrm{q}_{\mathrm{e}}}=\frac{1}{\mathrm{~K}_{\mathrm{L}} \mathrm{q}_{\max }}+\frac{\mathrm{C}_{\mathrm{e}}}{\mathrm{q}_{\max }}$

The linear plots between $\mathrm{C}_{\mathrm{e}} / \mathrm{q}_{\mathrm{e}} \mathrm{vs} . \mathrm{C}_{\mathrm{e}}$ are capable of providing $\mathrm{q}_{\max }$ and $\mathrm{K}_{\mathrm{L}}$ information.

Freundlich isotherm model is an empirical equation based on adsorption on a heterogeneous surface, and its logarithmic form is given in Eq. (2):

$\ln \mathrm{q}_{\mathrm{e}}=\frac{1}{\mathrm{n}} \ln \mathrm{C}_{\mathrm{e}}+\ln \mathrm{K}_{\mathrm{f}}$

Freundlich isotherm constants $1 / \mathrm{n}$ and $\mathrm{K}_{\mathrm{f}}$ were calculated from the slope and the intercept of the plot of $\ln \mathrm{q}_{\mathrm{e}}$ vs. $\ln \mathrm{C}_{\mathrm{e}}$, which are related to the measure of adsorption intensity or surface heterogeneity and capacity, respectively. The constant values for both models (Table 1) show that the adsorption of silicates on the membrane of this adsorbent follows the Freundlich model.

\section{Effect of Contact Time}

Fig. 7 shows the adsorption capacity of the CPEG membrane with $1 \%$ TOMAC for silicate ions at various contact times.

Fig. 7 shows that the adsorbent, CPEG composites, reached saturation at $60 \mathrm{~min}$ and remained almost constant afterward. Thus, the PEG/CPEG composites were found to be suitable for the adsorption of silicate ions from bulk solution onto the active sites of the solid surface, and the minimum time required for this process was $60 \mathrm{~min}$. Through modeling, the $\mathrm{q}_{t}$ vs. time experimental data was more suitable with the pseudosecond-order adsorption kinetics model compared to the first-order. The second-order model produced an $\mathrm{R}^{2}$ value of 0.9923 with a $\mathrm{q}_{\mathrm{e}}$ value of $40.0 \mathrm{mg} \mathrm{g}^{-1}$ and $\mathrm{k}_{2}$ of $1.13 \times 10^{-3} \mathrm{~g} \mathrm{mg}^{-1} \mathrm{~min}^{-1}$.

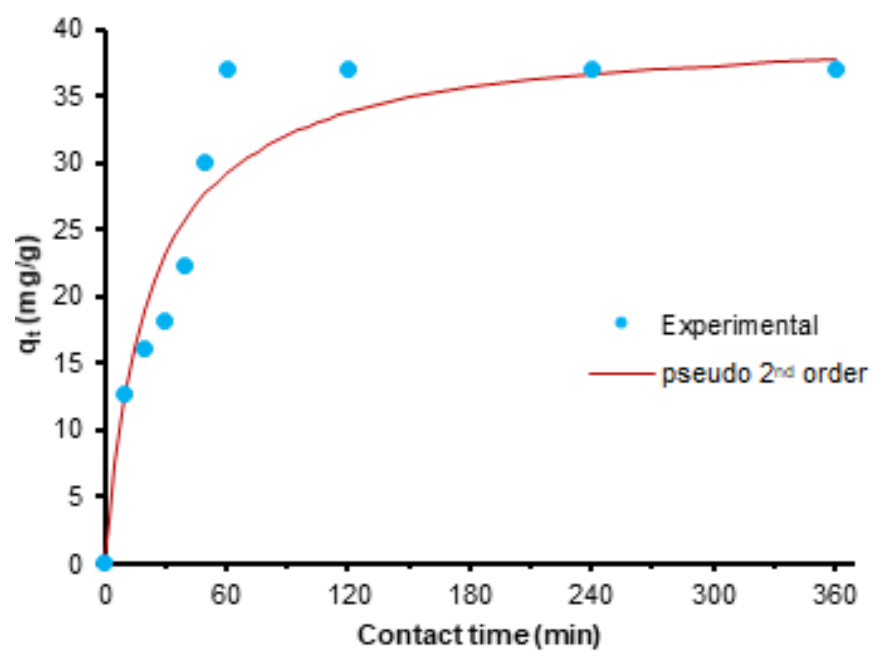

Fig 7. Effect of contact time on the adsorption capacity of the CPEG membrane with 1\% TOMAC

Table 1. Parameters for Freundlich and Langmuir isotherms for CPEG

\begin{tabular}{llll}
\hline Langmuir & & Freundlich & \\
\hline $\mathrm{q}_{\max }\left(\mathrm{mg} \mathrm{g}^{-1}\right)$ & 45.46 & $\mathrm{~K}_{\mathrm{f}}\left(\mathrm{mg} \mathrm{g}^{-1}\right)$ & 2.21 \\
$\mathrm{~K}\left(\mathrm{~L} \mathrm{mg}^{-1}\right)$ & $5.2 \times 10^{-4}$ & $\mathrm{~N}$ & 1.64 \\
$\mathrm{R}^{2}$ & 0.9382 & $\mathrm{R}^{2}$ & 0.9858 \\
\hline
\end{tabular}

Table 2. Information on the sampling location

\begin{tabular}{llllll}
\hline \multirow{2}{*}{ Information } & \multicolumn{5}{l}{ Location of Sample } \\
\cline { 2 - 6 } & Reactor 30 & Reactor 30A & Reactor 28 & Reactor 7B & Reactor 7C \\
\hline Latitude & -7.1938 & -7.1938 & -7.2035 & -7.2014 & -7.2006 \\
Longitude & 109.900 & 109.900 & 109.900 & 109.88 & 109.88 \\
Altitude & 2094.69 & 2094.69 & 2108.84 & 1948.74 & 2178.32 \\
Pressure (bar) & 0.76 & 0.76 & 0.76 & 0.76 & 0.76 \\
Water Temp $\left({ }^{\circ} \mathrm{C}\right)$ & 89.3 & 89.1 & 90.5 & 91.0 & 91.0 \\
Air Temp $\left({ }^{\circ} \mathrm{C}\right)$ & 21.0 & 21.0 & 20.0 & 20.0 & 20.0 \\
$\mathrm{pH}$ & 6.22 & 6.19 & 6.15 & 6.24 & 6.26 \\
\hline
\end{tabular}


Table 3. Comparison of the silicate ion adsorption capacity of CPEG with other reported adsorbents

\begin{tabular}{lccc}
\hline Adsorbent & Adsorbate & Adsorption capacity $\left(\mathrm{mg} \mathrm{g}^{-1}\right.$ & Reference \\
\hline Gallic-acid modified resin & Silicate & $4.64-4.94$ & {$[25]$} \\
Cation resin & Silicate & 6.6 & {$[16]$} \\
Geothite & Silicate & 6.12 & {$[26]$} \\
AA101 T20 & Silicate & 5.0 & {$[11]$} \\
AA101 T30 & Silicate & 7.5 & {$[11]$} \\
Ferrihydrite & Silicate & 34.2 & {$[27]$} \\
CPEG & Silicate & 72.6 & The current study \\
\hline
\end{tabular}

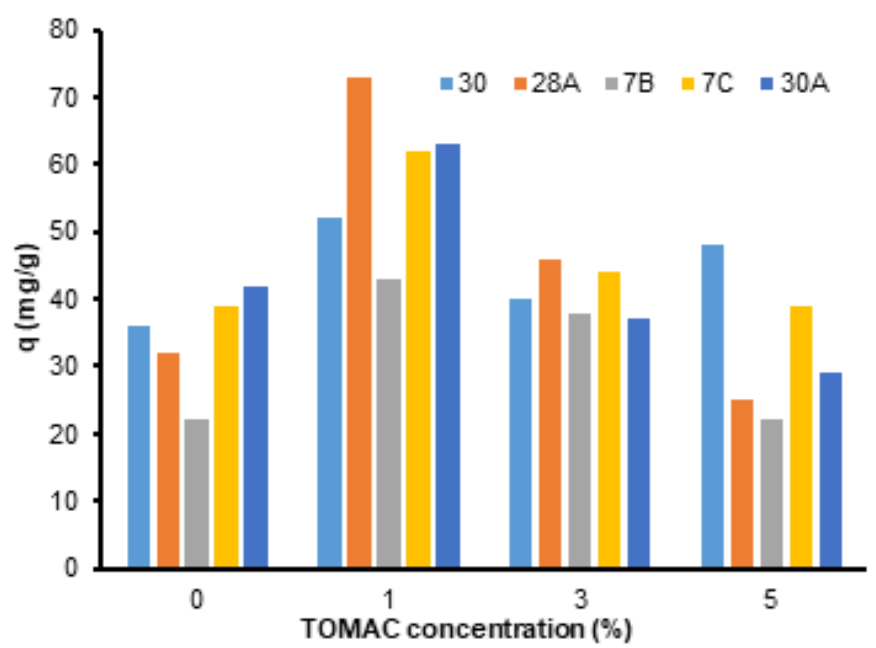

Fig 8. Effect of TOMA concentration on the adsorbent material capacity to adsorb silicate from the geothermal fluid of Geo Dipa

\section{Application of CPEG on Geo Dipa Dieng Geothermal Brine}

Geothermal fluid was obtained from Geo Dipa Dieng, and the reservoir condition is shown in Table 2.

The adsorbents were tested to remove silicate from the geothermal fluid. Fig. 8 shows the effect of TOMAC concentration on the material capacity. The adsorption capacity was high when the concentration of TOMAC was $1 \%$. This effect is mainly due to the strong electrostatic interaction between the positively charged sites of the adsorbent and the silicate anions and their entrapment in the pores. A comparison of the adsorption capacities of CPEG with other materials is given in Table 3 , which shows the advantages of the adsorbent being developed.

\section{- CONCLUSION}

In summary, CPEG composite materials were studied with different parameters, and the silicate ion adsorption capabilities of these adsorbents were also investigated. The number of ions adsorbed elevated with increasing concentration of silicate. The optimum $\mathrm{pH}$ for the adsorption was $\mathrm{pH} 6$, which is the average level for geothermal fluid. The adsorption isotherm data fit the Freundlich model, while the reaction rate followed second-order kinetics. The adsorption capacity $\left(\mathrm{q}_{\mathrm{e}}\right)$ of the prepared CPEG membrane with 1\% TOMAC was $72.6 \mathrm{mg} \mathrm{g}^{-1}$, higher than the other adsorbents. The results obtained in this study illustrated that PEG/Chitosan composites are promising materials for silicate ion removal from aqueous solutions in geothermal systems.

\section{- REFERENCES}

[1] Nasruddin, Alhamid, M.I., Daud, Y., Surachman, A., Sugiyono, A., Aditya, H.B., and Mahlia, T.M.I., 2016, The potential of geothermal energy for electricity generation in Indonesia: A review, Renewable Sustainable Energy Rev., 53, 733-740.

[2] Purnomo, B.J., and Pichler, T., 2014, Geothermal systems on the island of Java, Indonesia, J. Volcanol. Geotherm. Res., 285, 47-59.

[3] Pambudi, N.A., Itoi, R., Yamashiro, R., Syah Alam, B.Y.C.S.S., Tusara, L., Jalilinasrabady, S., and Khasani, J., 2015, The behavior of silica in geothermal brine from Dieng geothermal power plant, Indonesia, Geothermics, 54, 109-114.

[4] Wang, S., Xiong, Y., Winterfeld, P., Zhang, K., and Wu, Y.S., 2014, Parallel simulation of thermalhydrological-mechanic (THM) processes in geothermal reservoirs, Proceedings of the $39^{\text {th }}$ Workshop on Geothermal Reservoir Engineering, Stanford University, Stanford, California, February 24-26, 2014, 1-13. 
[5] Jamero, J., Zarrouk, S.J., and Mroczek, E., 2018, Mineral scaling in two-phase geothermal pipelines: Two case studies, Geothermics, 72, 1-14.

[6] Akın, T., and Karg1, H., 2019, Modeling the geochemical evolution of fluids in geothermal wells and its implication for sustainable energy production, Geothermics, 77, 115-129.

[7] Antony, A., Low, J.H., Gray, S., Childress, A.E., LeClech, P., and Leslie, G., 2011, Scale formation and control in high-pressure membrane water treatment systems: A review, J. Membr. Sci., 383 (1-2), 1-16.

[8] Pambudi, N.A., Itoi, R., Jalilinasrabady, S., and Gürtürk, M., 2018, Sustainability of geothermal power plant combined with thermodynamic and silica scaling model, Geothermics, 71, 108-117.

[9] Spinthaki, A., Matheis, J., Hater, W., and Demadis, K.D., 2018, Antiscalant-driven inhibition and stabilization of "magnesium silicate" under geothermal stresses: The role of magnesiumphosphonate coordination chemistry, Energy Fuels, 32 (11), 11749-11760.

[10] Neofotistou, E., and Demadis, K.D., 2004, Use of antiscalants for mitigation of silica, Desalination, 167, 257-272.

[11] Milne, N.A., O’Reilly, T., Sanciolo, P., Ostarcevic, E., Beighton, M., Taylor, K., Mullett, M., Tarquin, A.J., and Gray, S.R., 2014, Chemistry of silica scale mitigation for RO desalination with particular reference to remote operations, Water Res., 65, 107133.

[12] Hafez, O.M., Shoeib, M.A., El-Khateeb, M.A., AbdelShafy, H.I., and Youssef, A.O., 2018, Removal of scale forming species from cooling tower blowdown water by electrocoagulation using different electrodes, Chem. Eng. Res. Des., 136, 347-357.

[13] Sasan, K., Brady, P.V., Krumhansl, J.L., and Nenoff, T.M., 2017, Removal of dissolved silica from industrial waters using inorganic ion exchangers, $J$. Water Process Eng., 17, 117-123.

[14] Yin, W., Ai, J., Huang, L.Z., Tobler, D.J., and Hansen, H.C.B., 2018, A silicate/glycine switch to control the reactivity of layered iron(II)-iron(III) hydroxides for dechlorination of carbon tetrachloride, Environ. Sci. Technol., 52 (14), 7876-7883.

[15] Reimus, P., Dean, C., and Newell, D., 2018, Evaluation of a cation-exchanging tracer to interrogate fracture surface area in enhanced geothermal systems, Geothermics, 71, 12-23.

[16] Ali, M.B.S., Hamrouni, B., Bouguecha, S., and Dhahbi, M., 2004, Silica removal using ionexchange resins, Desalination, 167, 273-279.

[17] Gunnarsson, I., and Arnórsson, S., 2005, Impact of silica scaling on the efficiency of heat extraction from high-temperature geothermal fluids, Geothermics, 34 (3), 320-329.

[18] Soares, S.F., Rodrigues, M.I., Trindade, T., and Daniel-da-Silva, A.L., 2017, Chitosan-silica hybrid nanosorbents for oil removal from water, Colloids Surf., A, 532, 305-313.

[19] Monasterio, M., Gaitero, J.J., Manzano, H., Dolado, J.S., and Cerveny, S., 2015, Effect of chemical environment on the dynamics of water confined in calcium silicate minerals: Natural and synthetic tobermorite, Langmuir, 31 (17), 4964-4972.

[20] Moreira, A.L.S.L., Pereira, A.S., Speziali, M.G., Novack, K.M., Gurgel, L.V.A., and Gil, L.F., 2018, Bifunctionalized chitosan: A versatile adsorbent for removal of $\mathrm{Cu}(\mathrm{II})$ and $\mathrm{Cr}(\mathrm{VI})$ from aqueous solution, Carbohydr. Polym., 201, 218-227.

[21] Hasson, D., Shemer, H., and Sher, A., 2011, State of the art of friendly "green" scale control inhibitors: A review article, Ind. Eng. Chem. Res., 50 (12), 7601-7607.

[22] Rajeswari, A., Amalraj, A., and Pius, A., 2015, Removal of phosphate using chitosan-polymer composites, J. Environ. Chem. Eng., 3 (4), 2331-2341.

[23] Goyal, R.K., Jayakumar, N.S., and Hashim, M.A., 2011, Chromium removal by emulsion liquid membrane using $[\mathrm{BMIM}]^{+}\left[\mathrm{NTf}_{2}\right]^{-}$as stabilizer and TOMAC as extractant, Desalination, 278 (1-3), 5056.

[24] Wionczyk, B., and Apostoluk, W., 2005, Equilibria of Extraction of chromium(III) from alkaline solutions with trioctylmethylammonium chloride 
(aliquat 336), Hydrometallurgy, 78 (1-2 SPEC. ISS.), 116-128.

[25] Bai, S., Han, J., Du, C., and Ding, W., 2019, Selective removal of silicic acid by a gallic-acid modified resin, J. Water Reuse Desalin., 9 (4), 431-441.

[26] Hiemstra, T., Barnett, M.O., and van Riemsdijk, W.H.,
2007, Interaction of silicic acid with goethite, $J$. Colloid Interface Sci., 310 (1), 8-17.

[27] Hansen, H.C.B., Raben-Lange, B., RaulundRasmussen, K., and Borggaard, O.K., 1994, Monosilicate adsorption by ferrihydrite and goethite at pH 3-6, Soil Sci., 158 (1), 40-46. 